\title{
Pre- and post-diagnosis costs of tuberculosis to patients on Directly Observed Treatment Short course in districts of southwestern Ethiopia: a longitudinal study
}

Abyot Asres $^{1,3^{*}}$, Degu Jerene ${ }^{2}$ and Wakgari Deressa ${ }^{3}$

\begin{abstract}
Background: Financial burden on tuberculosis (TB) patients results in delayed treatment and poor compliance. We assessed pre- and post-diagnosis costs to TB patients.

Methods: A longitudinal study among 735 new TB cases was conducted from January 2015 through June 2016 in 10 woredas (districts) of southwestern Ethiopia. Direct out-of-pocket, payments, and lost income (indirect cost) were solicited from patients during the first 2 months and at the end of treatment. Thus, we ascertained direct medical, nonmedical, and indirect costs incurred by patients during pre- and post-diagnosis periods. We categorized costs incurred from onset of illness until TB diagnosis as pre-diagnosis and that incurred after diagnosis through treatment completion as post-diagnosis. Pre- and post-diagnosis costs constitute total cost incurred by the patients. We fitted linear regression model to identify predictors of cost.

Results: Between onset of illness and anti-TB treatment course, patients incurred a median (inter-quartile range (IQR)) of US\$201.48 (136.7-318.94). Of the total cost, the indirect and direct costs respectively constituted 70.6 and $29.4 \%$. TB patients incurred a median (IQR) of US\$97.62 (6.43-184.22) and US\$93.75 (56.91-141.54) during the pre- and post-diagnosis periods, respectively. Thus, patients incurred $53.6 \%$ of the total cost during the pre-diagnosis period. Direct out-of-pocket expenses during the pre- and post-diagnosis periods respectively amount to median (IQR) of US\$21.64 (10.23-48.31) and US\$35.02 (0-70.04). Patient delay days $(p<0.001)$, provider delay days $(p<0.001)$, number of healthcare facilities visited until TB diagnosis $(p<0.001)$, and TB diagnosis at private facilities $(p=0.02)$ independently predicted increased pre-diagnosis cost. Similarly, rural residence $(p<0.001)$, hospitalization during anti-TB treatment $(p<0.001)$, patient delay days $(p<0.001)$, and provider delay days $(p<0.001)$ predicted increased post-diagnosis costs.
\end{abstract}

Conclusion: TB patients incur substantial cost for care seeking and treatment despite "free service" for TB. Therefore, promoting early care seeking, decentralizing efficient diagnosis, and treatment services within reach of peoples, and introducing reimbursement system for direct costs can help minimize financial burden to the patient.

Keywords: TB, Direct cost, Indirect cost, Longitudinal, Pre-diagnosis, Post-diagnosis, Ethiopia

\footnotetext{
* Correspondence: abyotasres@gmail.com

'Department of Public Health, College of Health Sciences, Mizan-Tepi

University, PO Box 260, Mizan Aman, Ethiopia

${ }^{3}$ Department of Preventive Medicine, School of Public Health, College of

Health Sciences, Addis Ababa University, Addis Ababa, Ethiopia

Full list of author information is available at the end of the article
}

(C) The Author(s). 2018 Open Access This article is distributed under the terms of the Creative Commons Attribution 4.0 International License (http://creativecommons.org/licenses/by/4.0/), which permits unrestricted use, distribution, and reproduction in any medium, provided you give appropriate credit to the original author(s) and the source, provide a link to the Creative Commons license, and indicate if changes were made. The Creative Commons Public Domain Dedication waiver (http://creativecommons.org/publicdomain/zero/1.0/) applies to the data made available in this article, unless otherwise stated. 


\section{Background}

Tuberculosis (TB) remained among the major global public health problems. In 2015, an estimated 10.4 million cases and 1.4 million deaths occurred globally. The African Region constitutes $28 \%$ of the global cases and the most severe burden relative to population (281 cases per 100,000 people) [1]. TB morbidity and mortality pose an enormous economic burden to patients, household, and society. Each year, a TB patient loses on average 3 to 4 months of work and up to $30 \%$ of household earnings [2].

Efforts to control TB have three distinct, but overlapping humanitarian, public health, and economic dimensions. The efforts imply timely diagnosis and treatment of patients and reduction of costs due to TB [3]. The latest TB control strategy, End TB, underlined the need for universal access to health services without financial hardship, social protection for income replacement, and support in the event of illness [4]. Accordingly, a global target has been set to have no TB-affected family facing catastrophic costs due to TB by $2020[4,5]$. Costs incurred by a TB patient include either direct or indirect costs. The direct costs comprise out-of-pocket expenses for medical and nonmedical services whereas the indirect costs constitute foregone income because of lost workdays [6].

Despite the free TB diagnosis and treatment, TB patients and families incur high direct and indirect costs due to TB illness [5]. Systematic reviews across low- and middle-income countries showed mean total costs of TB ranging from fewer than I\$1 to I\$8198 $[5,7]$. The review further reported indirect and direct costs incurred for TB care respectively constituted 60 and $40 \%$ of the total cost [5]. Studies also reported that seeking care and treatment of TB costs a median of United States of America Dollar (US\$) 592 in Nigeria [8] and mean cost of US\$108.4 in Yemen [9] per household. The high cost of TB care seeking and treatment result in delays to diagnoses $[10,11]$ and poor outcome $[12,13]$. The poor outcome lead to development of drug resistant TB [14] that require much higher cost of care [15].

Implementation of global TB control strategies in Ethiopia have led to improvements in access to TB care, decline in TB morbidity, and mortality [16]. Nonetheless, Ethiopia belongs to the $14 \mathrm{~TB}, \mathrm{~TB} /$ human immunodeficiency virus (HIV), and multi-drug resistant (MDR) TB high-burden countries [1]. Out of a total US\$47.8 million spent for TB control in 2008, household out-ofpocket expenses constituted 62\% [17]. A cost and epidemiological modelling in Ethiopia, showed out-ofpocket medical cost for TB amounted to US $\$ 49$ per patient that led households to fall below poverty line [18]. A study in Tigray, Northern Ethiopia from patient perspective reported median cost incurred for care seeking to be US\$16 [19]. A community randomized trial using societal perspective in southern Ethiopia revealed a successful treatment of a smear-positive patient costs US $\$ 158.9$ at a health facility compared to that within the community (US\$61.7) [20].

It is important to understand the financial burden of TB patients to adapt and realize a global target of having no households incurring catastrophic costs because of TB [1]. However, only few studies exist in Ethiopia, those dealt on the financial burden of TB patients. The few studies dealt on cost of care seeking and diagnosis [19] or cost of treatment [20] but not both. The studies were conducted during the 8 months of treatment regimen. However, the current 6 -month regimen requires frequent visits (daily to weekly) to health facilities throughout the course of treatment [21]. Furthermore, none of the studies analyzed cost predictors across the continuum of care. Generally, evidences on financial burden posed to TB patients across the pathways to treatment are limited in Ethiopia. Therefore, we studied costs incurred by TB patients across the pre- and postdiagnosis periods including cost drivers in districts of southwestern Ethiopia.

\section{Methods}

\section{Study setting and design}

A longitudinal study among new TB cases on Directly Observed Treatment Short course (DOTS) was carried out from January 2015 through June 2016. We included 14 public healthcare facilities (three hospitals and 11 health centers) from 10 woredas (an administrative unit equivalent to district) in three zones (an administrative structure that oversees woredas and report to regional states). The zones, Bench Maji, Kaffa, and Sheka, are among the 15 zones in Southern Nations Nationalities and Peoples Region (SNNPR). The zones are located at the southwestern border of the region where an estimated 2,064,102 people reside [22]. The zones are organized into four town administrations and 26 woredas. During the study, three hospitals and 65 health centers were providing TB DOTS [23].

Diagnosis and treatment for all forms of $\mathrm{TB}$ in Ethiopia is according to a national guidelines [21, 24] that specify case definitions, diagnostic, and treatment standards. Diagnosis based on sputum microscopy, sputum follow-up test, and anti-TB drugs are free of charge in all public and selected private facilities. Since the end of 2011, all forms of new TB cases are treated for 6 months with combination of rifampicin (R), isoniazid $(\mathrm{H})$, pyramidal $(\mathrm{Z})$, and ethambutol $(\mathrm{E})$ for the first 2 months (intensive phase) (2RHZE) followed by rifampicin $(\mathrm{R})$ and isoniazid $(\mathrm{H})$ for 4 months $(4 \mathrm{RH})$. Thus, patients need to visit a DOTS center daily and weekly during intensive and continuation phase treatments, respectively. 


\section{Sample size and sampling}

The sample size needed for the study was calculated using STATA V13 considering a mean (SD) patient cost of care seeking of US\$29(14) [19] to detect a US\$5 difference which revealed 250 cases. This study is part of a doctoral dissertation aimed at assessing time delays, cost, and outcomes of TB patients on DOTS. Thus, among the sample sizes calculated for each objective of the dissertation, which required for assessing predictors of delay, 802 cases was the largest. Since similar cases were studied for all the objectives, the largest sample, 802 cases was used for this study.

We selected the region (SNNPR) and zones (Bench Maji, Kaffa, and Sheka) conveniently. Considering the available resources and representativeness, we decided to study 10 woredas of the three zones. Thus, through proportional allocation, we determined the number of woredas from each zone. Considering the number of TB cases notified in the preceding year to the study time, we selected the woredas from each zones. Then, all public health facilities providing diagnosis and treatment of TB in the selected woredas were included for the study. We included 14 health facilities (three hospitals and 11 health centers). Therefore, we allocated the 802 cases proportionally to the zones, woredas, and health facilities based on their preceding year TB case notification. Finally, successive consenting cases were enrolled until the required sample reaches. Those new cases, older than 18 years and on intensive phase treatment, were included and those on continuation phase, transferred to other treatment center, lost to follow-up, and died before the enrollment were excluded from study.

\section{Data collection}

Data were collected using structured questionnaire (Additional file 1) adapted from the tool to estimate TB patients' cost developed by the WHO and other partners [6]. Similarly, data abstraction checklist was prepared to extract data from the standard unit TB register. The questionnaire was translated in to the national language (Amharic) to ease the understanding among both the data collectors and participants. Then, 10 diploma graduate nurse data collectors and three master holder supervisors were recruited and trained for 3 days. The training included the basics of TB control, details of questionnaire, data abstraction, interviewing techniques, and pretest of the tool at health facilities not included in the study. Finally, eligible cases were traced from the unit TB register, and face-to-face interview was held within the intensive phase and end of treatment. The first interview-included patients' sociodemographic, healthcare-seeking practices, and costs incurred until TB diagnosis (pre-diagnosis cost). The follow-up interview inquired costs incurred after the diagnosis of TB through completion of the treatment (post-diagnosis cost).

\section{Cost ascertainment}

Cost data were ascertained from patient perspective using prevalent approach that estimate financial burden of an illness to patients at specified period of time [25]. So costs incurred by patients for care seeking and treatment of TB were collected at two-time points, during the first 2 months of treatment and at the end of the treatment. Both direct out-of-pocket expenses (for medical and nonmedical services) and indirect costs were measured. Direct costs consisted of out-of-pocket charges for medical services (consultation, drugs, laboratory tests, X-ray, and hospitalization) and nonmedical services (transportation, meal, and accommodation) while visiting healthcare facilities.

Direct out-of-pocket patient expenses during the prediagnosis period (incurred from onset of illness to treatment initiation) were determined by asking patient expense at each visit for consultation, laboratory tests, drugs, transportation, meals, and lodging. In the same way, post-diagnosis direct costs (incurred from initiation to completion of the prescribed treatment) were measured by inquiring patients' medical and nonmedical expenses during visits for anti-TB treatment. The number of visits for the pre-diagnosis period was solicited from patients, and post-diagnosis visits were taken from attendance records on a unit register. Thus, transportation cost was calculated by multiplying the number of visits with the fee per trip.

The indirect costs were estimated using the human capital approach. Patients were requested to estimate time lost due to sickness and visits for consultation, hospitalization, drug collection, and trip journey. The time spent second or minute were converted to hours and then to days at an average of eight working hours in a day $(8 \mathrm{~h}=1$ day). Finally, the number of days was multiplied by an average daily wage rate of US $\$ 2.43=50$ Ethiopian Birr for those unemployed and daily rate calculated from their gross monthly salary for those formally employed. Monthly income of formally employed cases was inquired from patients by asking their monthly salary. For self-employed, self-estimated average monthly earning was used to calculate daily rate. An average wage rate estimated by the social affair offices was used for unemployed cases.

For cost items with no charge, it was recorded as zero. All the costs were inquired in local currency, Ethiopian Birr (ETB), and then converted into US dollars (US\$) using the average exchange rate of (US\$1 $=20.56$ ETB) during January through December 2015 [26]. 


\section{Data management}

Data were entered into EpiData v3.1 then exported to SPSS version 21 for cleaning and then to STATA 13 for analysis. The data were described using frequency, proportions, mean (standard deviation), and median (interquartile range), and normality of the cost data were checked using plots (Q-Q plots and/or histograms) or Kolmogorov-Smirnov test. The cost data were right skewed and became log normal upon log transformation to base 10 . Hence, all the statistical tests were done with the lognormal data and reported by back transforming to its anti-log.

Proportion and mean differences across categorical variables were tested using chi-square and independent $t$ tests respectively. Associations between continuous variables were tested with simple correlation. Mean difference between pre- and post-diagnosis costs were tested with paired $t$ test. Finally, simple and multiple linear regression models were fitted to identify predictors of pre- and post-TB diagnosis costs. Assumptions and fitness for the linear regression model were assessed and ensured. In all the statistical tests, significance was judged at $p<0.05$.

\section{Ethical issues}

The Institutional Review Board of the College of Health Sciences at Addis Ababa University approved the study protocol. Therefore, patients consented in written for the interview and clinical records of patients were retrieved upon permission from the respective health facilities.

\section{Operational definitions}

Patient delay is days elapsed between onsets of illness to the first formal healthcare seeking.

Health system/provider delay is the number of days spent between the first consultations to initiation of treatments.

Total delay is the number of days elapsed since onset of illness to anti-TB treatment initiation.

Medical cost is costs incurred for medical services including consultation, laboratory tests, drugs other than anti-TB, X-ray, and related services.

Nonmedical cost is costs incurred for transportation, accommodation, meal, and related services while seeking care for TB and visiting to collect anti-TB drugs.

Direct cost is out-of-pocket patient expenses for medical or nonmedical services while seeking care, diagnosis, and treatment for TB.

Indirect cost is lost earning because of inability to work or lost workdays while traveling to seek care, diagnosis, and treatment for TB.

Pre-diagnosis cost is the cost incurred since onset of illness until anti-TB treatment initiation.
Post-diagnosis cost is the cost incurred since the beginning up to the completion of anti-TB treatment.

Total cost is both direct and indirect costs incurred for care seeking, diagnosis, and treatment of TB.

\section{Results}

A total of 735 TB cases were enrolled of which $627(85.3 \%)$ completed the follow-up. Those lost included 29(3.9\%) deaths, $36(4.9 \%)$ transferred to other treatment centers, $5(0.7 \%)$ treatment failure, and 38(5.2\%) lost to follow-up. Nonetheless, there were no statistical significant differences with the proportions of the attributes across the baseline and end line surveys (Table 1). The median age (inter-quartile range (IQR)) of the cases during enrollment (baseline) was 27(20-37) years. Of the cases enrolled, 53 and $29.4 \%$ completed elementary school and are involved in farming, respectively. The mean $(+\mathrm{SD})$ of size and median annual income of the households were $4.3(+2.1)$ and US\$466.93, respectively.

\section{Care-seeking pathways}

TB patients first visited a healthcare facility after a median of 25 days from onset of illness (patient delay). Thus, 35.4 and $32.4 \%$ of the cases first visited private clinics and public health centers, respectively (Table 2). The rest of the cases first visited hospitals (30.1\%) and health posts (2.1\%). TB diagnosis of $448(61 \%)$ cases was made at a hospital, and for 244(33.2\%), the diagnosis was made at the first visited health facility. Diagnosis of $491(66.8 \%)$ were reached after an average $(+\mathrm{SD})$ of $3.6(+2.4)$ visits to an average $(+\mathrm{SD})$ of $2.2(+1.2)$ healthcare facilities (HCF). Since the first consultation, a median of 22 days had been elapsed to initiate antiTB treatment. Among the cases, 586(79.7\%) had pulmonary TB and 362(49.3\%) were diagnosed clinically. All of the cases were offered HIV screening test of whom 68 (9.3\%) tested positive, 95\% CI (7.2-11.3\%).

\section{Pre-diagnosis cost}

Until diagnosis of TB, patients incurred a median (IQR) cost of US\$97.6 (56.4-184.2) (Table 3). Direct cost amount to median (IQR) US\$21.64 (10.23-48.31) and constitute $25.6 \%$ (Fig. 1) of the total pre-diagnosis costs. Patients had lost median (IQR) of 24.7(15.1-48.4) workdays until diagnosis of TB that corresponded to median (IQR) US\$64.45 (39.8-128.8) income loss.

The pre-diagnosis cost was positively correlated with patient $(\gamma=0.32, p<0.001)$, provider $(\gamma=0.64, p<0.001)$ and total delays $(\gamma=0.68, p<0.001)$, and the number of HCF visited until diagnosis $(\gamma=0.42, p<0.001)$. The mean pre-diagnosis cost was significantly different across the types of $\mathrm{TB}(\mathrm{F}=10.03, p<0.00)$, type of first visited HCF $(p=0.002)$, HCF where diagnosis was made $(p<0.001)$, and mode of diagnosis $(p=0.001)$ (Additional file 2: Table S1). 
Table 1 Sociodemographic characteristics of TB cases in districts of southwestern Ethiopia, January to December 2015

\begin{tabular}{|c|c|c|c|c|}
\hline Variable & & $\begin{array}{l}\text { Baseline }(n=735) \\
n(\%)\end{array}$ & $\begin{array}{l}\text { End line }(n=627) \\
n(\%)\end{array}$ & $P$ value \\
\hline Gender & Female & 288(39.2) & 244(38.9) & 0.9 \\
\hline \multirow[t]{3}{*}{ Age(years) } & $18-34$ & $503(68.4)$ & $431(68.7)$ & 0.9 \\
\hline & $35-65$ & $216(29.4)$ & 183(29.1) & 0.8 \\
\hline & $>65$ & $16(2.2)$ & $13(2.1)$ & 0.89 \\
\hline \multirow[t]{3}{*}{ Marital status } & Never married & 275(37.4) & $235(37.5)$ & 0.97 \\
\hline & Currently married & $404(55)$ & $342(54.5)$ & 0.85 \\
\hline & Widowed/divorced & $56(7.6)$ & $50(8)$ & 0.78 \\
\hline \multirow[t]{3}{*}{ Educational status } & No formal education & 212(28.8) & $176(28.1)$ & 0.77 \\
\hline & Completed elementary & $389(53)$ & $340(54.2)$ & 0.66 \\
\hline & Secondary and above & 134(18.2) & $111(17.7)$ & 0.8 \\
\hline \multirow[t]{4}{*}{ Occupation } & Employed & 172(23.4) & 147(23.4) & 1.00 \\
\hline & Farming & $216(29.4)$ & 188(30.0) & 0.81 \\
\hline & Unskilled work ${ }^{a}$ & $51(6.9)$ & $43(6.9)$ & 1.00 \\
\hline & Dependents ${ }^{\mathrm{b}}$ & $296(40.3)$ & 249(39.7) & 0.82 \\
\hline \multirow[t]{2}{*}{ Residence } & Urban & $369(50.2)$ & $313(49.9)$ & 0.94 \\
\hline & Rural & $367(49.9)$ & $314(50.1)$ & 0.74 \\
\hline \multirow[t]{2}{*}{ Household main income earner } & Self & $370(50.3)$ & $310(49.4)$ & 0.74 \\
\hline & Other $^{c}$ & $365(49.7)$ & $317(50.6)$ & 0.8 \\
\hline \multirow[t]{2}{*}{ Household income } & $\leq$ US\$466.93 & 288(50.6) & $242(50.3)$ & 0.9 \\
\hline & $>$ US\$466.93 & $281(49.4)$ & 239(49.7) & 0.9 \\
\hline
\end{tabular}

${ }^{\mathrm{a}}$ Housemaid, daily laborer

${ }^{\text {b }}$ Students, housewife

${ }^{\mathrm{c}}$ Father/mother/husband/wife/brother/sister/employer

In a multiple regression patient and provider delays, being clinically diagnosed, TB diagnosis at private facilities and the number of visited healthcare facilities independently predicted higher mean pre-diagnosis costs (Table 4). Every single patient and provider delay days each increased the mean pre-diagnosis cost by $0.5 \%$. Those patients' diagnosed clinically incurred $11 \%$ higher mean pre-diagnosis costs compared to those diagnosed bacteriologically. Similarly, patients diagnosed at private HCFs incurred 18\% higher mean pre-diagnosis cost compared to those diagnosed at public HCFs.

\section{Post-diagnosis cost}

After the diagnosis of TB, patients incurred a total median (IQR) of US\$93.75 (56.9-141.54) until the completion of the treatment (Table 3). The direct cost amounted to a median (IQR) of US\$35.02 (0-70.04) and constitutes $35.9 \%$ (Fig. 1) of the total post-diagnosis cost. During the treatment, TB patients had lost a median (IQR) of 21(13-35.3) workdays that corresponded to a median (IQR) of US\$51.0 (34.6-97.0) income loss (indirect cost). Thus, significantly lower medical and indirect costs and higher nonmedical costs were incurred during the post-diagnosis period compared to the pre-diagnosis. The post-diagnosis cost was positively correlated with patient $(\gamma=0.20, p<0.001)$ and provider $(\gamma=0.23, p<0.001)$ delays.

In the multiple regression analysis, being a rural resident, having a travel time beyond $1 \mathrm{~h}$ to the treatment center, being admitted for anti-TB treatment, patient and provider delays independently predicted higher mean post-diagnosis cost. On the other hand, completing primary and higher educational status and being treated at a hospital predicted lower mean post-diagnosis costs (Table 5). Thus, being a rural resident was associated with an increase in mean post-diagnosis cost by $48 \%$ compared to those being urban residents. Every patient and provider delay days increases the mean post-diagnosis cost by 0.3 and $0.2 \%$, respectively. Those patients hospitalized for anti-TB treatment had more than twofold higher mean post-diagnosis cost compared to those patients never hospitalized for anti-TB treatment. Patients who followed their course of anti-TB treatment at hospitals had about $18 \%$ lower mean post-diagnosis cost compared to those who received the anti-TB treatment at health centers. 
Table 2 Care-seeking pathways and clinical characteristics of TB cases on treatment in districts of southwestern Ethiopia, January to December 2015

\begin{tabular}{|c|c|c|c|c|}
\hline \multirow[t]{2}{*}{ Variable } & & \multirow{2}{*}{$\begin{array}{l}\text { Baseline }(n=735) \\
n(\%)\end{array}$} & \multirow{2}{*}{$\begin{array}{l}\text { End line }(n=627) \\
n(\%)\end{array}$} & \multirow[t]{2}{*}{$P$ value } \\
\hline & & & & \\
\hline \multirow[t]{2}{*}{ Action to illness before visiting HCF } & None & $586(79.7)$ & 497(79.3) & 0.85 \\
\hline & Took action $^{\mathrm{a}}$ & $149(20.3)$ & 130(20.7) & 0.85 \\
\hline \multirow[t]{2}{*}{ First visited HCF } & DOTS center & $459(62.5)$ & $387(61.7)$ & 0.85 \\
\hline & Non-DOTS & $276(37.5)$ & 240(38.3) & 0.76 \\
\hline \multirow[t]{2}{*}{ Diagnosis made HCF } & Public & $636(86.5)$ & $537(85.6)$ & 0.76 \\
\hline & Private & $99(13.5)$ & $90(14.4)$ & 0.70 \\
\hline \multirow[t]{3}{*}{ Type of TB } & Pulmonary positive & $373(50.7)$ & $320(51.0))$ & 0.90 \\
\hline & Pulmonary negative & $213(29.0)$ & $176(28.1)$ & 0.70 \\
\hline & Extra pulmonary & $149(20.3)$ & 131(20.9) & 0.70 \\
\hline \multirow[t]{2}{*}{ Mode of diagnosis } & Bacteriological & $373(50.7)$ & $319(50.9)$ & 0.90 \\
\hline & Clinical & $362(49.3)$ & $308(49.1)$ & 0.90 \\
\hline \multirow[t]{2}{*}{ Treatment center } & Health center & $469(36.2)$ & $408(65.1)$ & 0.70 \\
\hline & Hospital & $266(63.8)$ & 219(34.9) & 0.70 \\
\hline \multirow[t]{2}{*}{ Travel time to treatment center } & $\leq 1 \mathrm{~h}$ & $437(59.5)$ & $373(59.5)$ & 1.00 \\
\hline & $>1 \mathrm{~h}$ & $298(40.5)$ & $254(40.5)$ & 1.00 \\
\hline Hospitalized for treatment & Yes & $19(2.6)$ & $15(2.4)$ & 0.40 \\
\hline HIV co-infection & Yes & $68(9.3)$ & $46(7.3)$ & 0.10 \\
\hline Patient delay & Median (IQR) days & $25((15-36)$ & $23(14-34)$ & 0.20 \\
\hline Provider delay & Median (IQR) days & $22(9-48)$ & $20(8-48)$ & 0.40 \\
\hline Total delay & Median (IQR) days & $55(32-100)$ & $52(31-93)$ & 0.50 \\
\hline
\end{tabular}

${ }^{a}$ Self-treatment, consult traditional healer, used holy water

Total cost of TB care seeking and treatment

Total costs incurred by patients for care seeking, diagnosis, and treatment amount to a median (IQR) of US\$201.48 (136.70-318.94) (Table 3). Pre- and post-diagnosis costs respectively constituted 53.6 and $46.4 \%$ of the total cost. Total direct cost constituted $29.4 \%$ (Fig. 1) of the total cost and amounted to a median (IQR) of US\$59.58 (29.43-113.81). Drugs other than anti-TB and diagnostic tests (laboratory or imaging tests) corresponded to 49.7 and $44.6 \%$ of the total medical costs, respectively. During the care seeking and treatment visits, patients had totally lost a median (IQR) 51.7 (32.0-80.8) workdays that corresponded to a median (IQR) of US\$127.68 (78.43-201.85) income loss (indirect cost). Out of the total forgone income due to the TB illness, the loss due to lost workdays following careseeking visits amounted to a median (IQR) of US\$18.02

Table 3 Distribution of TB patient costs across cost categories and periods in districts of southwestern Ethiopia, January to December 2015

\begin{tabular}{|c|c|c|c|c|}
\hline \multirow[t]{2}{*}{ Cost category } & & \multicolumn{3}{|l|}{ Cost period } \\
\hline & & Pre-diagnosis (US\$) & Post-diagnosis (US\$) & Total (US\$) \\
\hline \multirow[t]{2}{*}{ Medical } & Mean $(95 \% \mathrm{Cl})$ & $8.56(7.68,9.54)$ & $4.4(3.23,6.0)$ & $8.75(7.85,9.75)$ \\
\hline & Median (IQR) & $10.72(4.58,23.76)$ & $0(0)$ & $11.19(4.73-24.08)$ \\
\hline \multirow[t]{2}{*}{ Nonmedical } & Mean $(95 \% \mathrm{Cl})$ & $10.08(8.99,11.30)$ & $43.27(38.32,48.23))$ & $64.1(58.34,69.9)$ \\
\hline & Median (IQR) & $8.27(1.61,24.32)$ & $35.02(0-70.04)$ & $37.11(14.35,85.12)$ \\
\hline \multirow[t]{2}{*}{ Total direct } & Mean $(95 \% \mathrm{Cl})$ & $21.46(19.65,23.43)$ & $43.80(38.82,48.78)$ & $84.82(77.92,91.72)$ \\
\hline & Median (IQR) & $21.64(10.23,48.31)$ & $35.02(0-70.04)$ & $59.58(29.43,113.81)$ \\
\hline \multirow[t]{2}{*}{ Indirect } & Mean $(95 \% \mathrm{Cl})$ & $75.62(70.68,80.90)$ & $75.20(69.14,81.26))$ & $140.31(132.35,148.74)$ \\
\hline & Median (IQR) & $64.45(39.82,128.80)$ & $51.07(34.65,93.02)$ & $127.68(78.43,201.85)$ \\
\hline \multirow[t]{2}{*}{ Total } & Mean $(95 \% \mathrm{Cl})$ & $108.0(101.31,115.11)$ & $117.0(110.47,123.87)$ & $244.71(229.45,260.98)$ \\
\hline & Median (IQR) & $97.62(56.43,184.22)$ & $93.75(56.91,141.54)$ & $201.48(136.7,318.94)$ \\
\hline
\end{tabular}




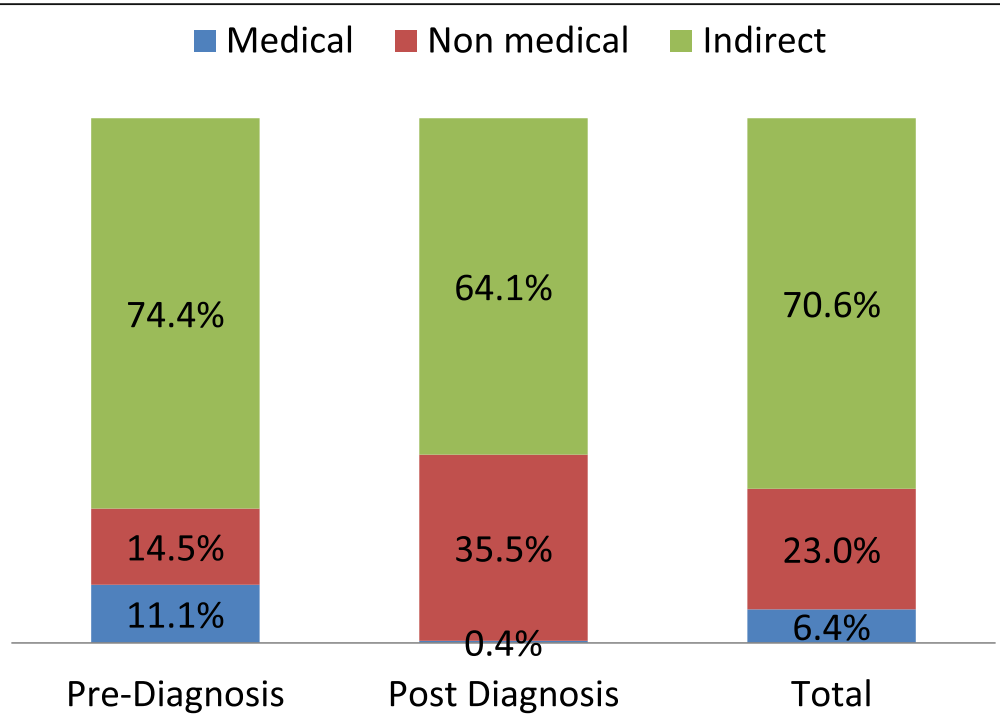

Fig. 1 Distribution of TB patient costs across pre and post diagnosis periods in districts of southwestern ethiopia January 2015 to June 2016

(11.35-30.85) that constitutes $28.4 \%$ of the total indirect cost. For $471 / 569(82.8 \%)$ of the cases, the total cost represents more than $10 \%$ of their estimated household annual income.

The mean total cost is significantly different across the types of $\mathrm{TB}(\mathrm{F}=3.68, p=0.03)$, action taken before $\mathrm{HCF}$ visit $(p=0.01)$, travel time to treatment center $(p=0.001)$, and hospitalization for anti-TB treatment $(p=0.005)$ (Additional file 2: Table S1). In multiple regression, rural residence, travel time to treatment center beyond $1 \mathrm{~h}$, action taken before HCF visit, hospitalized for anti-TB treatment, number of visited HCF, and patient and

Table 4 Predictors of pre-diagnosis cost among TB cases on treatment in districts of southwestern Ethiopia January to December 2015

\begin{tabular}{|c|c|c|c|c|c|c|}
\hline \multicolumn{2}{|l|}{ Variable } & \multirow{2}{*}{$\begin{array}{l}\text { Mean(SD) (US\$) } \\
112.62(0.12)\end{array}$} & \multirow{2}{*}{ 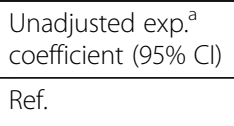 } & \multirow[t]{2}{*}{$P$ value } & \multirow{2}{*}{$\begin{array}{l}\text { Adjusted exp. } \\
\text { coefficient }(95 \% \text { Cl) } \\
\text { Ref. }\end{array}$} & \multirow[t]{2}{*}{$P$ value } \\
\hline Gender & Male & & & & & \\
\hline & Female & $101.25(0.11)$ & $0.90(0.79,1.02)$ & 0.1 & $0.94(0.86,1.03)$ & 0.20 \\
\hline \multirow[t]{2}{*}{ HIV result } & Positive & $131.2(0.13)$ & $1.24(0.98,1.55)$ & 0.07 & $1.16(0.99,1.36)$ & 0.06 \\
\hline & Negative & $106.02(0.11)$ & Ref. & & Ref. & \\
\hline \multirow[t]{2}{*}{ Mode of diagnosis } & Bacteriological & $97.00(0.11)$ & Ref. & & Ref. & \\
\hline & Clinical & $121.08(0.12)$ & $1.25(1.10,1.42)$ & 0.001 & $1.08(0.99,1.18)$ & 0.09 \\
\hline \multirow[t]{2}{*}{ Residence } & Urban & $114.61(0.12)$ & Ref. & & Ref. & \\
\hline & Rural & $102.13(0.1)$ & $0.89(0.78,1.01)$ & 0.07 & & \\
\hline \multicolumn{2}{|l|}{ Patient delay ${ }^{\complement}$ (days) } & & $1.006(1.005,1.006)$ & $<0.001$ & $1.005(1.004,1.01)$ & $<0.001^{*}$ \\
\hline \multicolumn{2}{|l|}{ Provider delay ${ }^{\complement}$ (days) } & & $1.006(1.005,1.01)$ & $<0.001$ & $1.005(1.004,1.01)$ & $<0.001^{*}$ \\
\hline \multirow[t]{2}{*}{ Action before HCF visit } & None & $106.72(0.12)$ & Ref. & & Ref. & \\
\hline & Took action $^{d}$ & $113.41(0.11)$ & $1.23(1.07,1.41)$ & 0.03 & $1.15(1.03,1.28)$ & 0.01 \\
\hline \multirow[t]{2}{*}{ First visited HCF } & DOTS center & $99.97(0.11)$ & Ref. & & Ref. & \\
\hline & Non-DOTS center & $122.57(0.11)$ & $1.23(1.07,1.40)$ & 0.002 & $1.01(0.91,1.11)$ & 0.8 \\
\hline \multirow[t]{2}{*}{ TB diagnosed HCF } & Public & 101.78(0.11) & Ref. & & Ref. & \\
\hline & Private & $153.88(0.13)$ & $1.5(1.26,1.81)$ & $<0.001$ & $1.18(1.03,1.34)$ & $0.02^{*}$ \\
\hline \multicolumn{3}{|c|}{ Number of HCF visited until diagnosis ${ }^{b}$} & $1.40(1.34,1.47)$ & $<0.001$ & $1.18(1.13,1.23)$ & $<0.001^{*}$ \\
\hline
\end{tabular}

*Statistically significant at $p<0.05$

${ }^{a}$ Exponent to the power of 10

${ }^{\mathrm{b}}$ Adjusted for all the variables listed in the table

'Variable treated as continuous

${ }^{\mathrm{d} S e l f-t r e a t m e n t, ~ u s e d ~ h o l y ~ w a t e r, ~ c o n s u l t ~ t r a d i t i o n a l ~ h e a l e r ~}$ 
Table 5 Predictors of post-diagnosis cost among TB cases on treatment in districts of southwestern Ethiopia January to December 2015

\begin{tabular}{|c|c|c|c|c|c|c|}
\hline Variable & & Mean(SD) & $\begin{array}{l}\text { Unadjusted } \exp ^{\mathrm{a}} \\
\text { coefficient }(95 \% \mathrm{Cl})\end{array}$ & $P$ value & $\begin{array}{l}\text { Adjusted } \exp ^{\mathrm{b}} \\
\text { coefficient }(95 \% \mathrm{Cl})\end{array}$ & $P$ value \\
\hline \multirow[t]{2}{*}{ Gender } & Male & $119.73(0.1)$ & Ref. & & Ref. & \\
\hline & Female & $112.51(0.1)$ & $0.94(0.83,1.06)$ & 0.3 & $0.92(0.83,1.02)$ & 0.07 \\
\hline \multirow[t]{2}{*}{ Residence } & Urban & $94.02(0.11)$ & & & & \\
\hline & Rural & $154.7(0.08)$ & $1.64(1.48,1.83)$ & $<0.001$ & $1.48(1.34,1.64)$ & $<0.001^{*}$ \\
\hline \multirow[t]{3}{*}{ Educational status } & Illiterate & 137.15(0.09) & Ref & & Ref & \\
\hline & Primary & $117.35(0.09)$ & $0.86(0.74,0.98)$ & 0.03 & $0.87(0.77,0.97)$ & $0.02^{*}$ \\
\hline & Secondary and above & $97.79(0.08)$ & $0.71(0.60,0.84)$ & $<0.001$ & $0.83(0.72,0.95)$ & $0.01^{*}$ \\
\hline \multirow[t]{2}{*}{ HIV result } & Positive & $123.52(0.1)$ & $1.06(0.88,1.28)$ & 0.5 & $1.13(0.97,1.30)$ & 0.1 \\
\hline & Negative & $116.20(0.1)$ & Ref. & & Ref. & \\
\hline \multirow[t]{2}{*}{ Mode of diagnosis } & Bacteriological & $118.25(0.1)$ & Ref. & & Ref. & \\
\hline & Clinical & $115.82(0.1)$ & $0.98(0.87,1.10)$ & 0.7 & $0.96(0.87,1.05)$ & 0.3 \\
\hline \multirow[t]{2}{*}{ Treatment center } & Hospital & $103.05(0.1)$ & $0.78(0.70,0.88)$ & $<0.001$ & $0.82(0.74,0.90)$ & $<0.001^{*}$ \\
\hline & Health center & $131.43(0.1)$ & & & & \\
\hline \multirow[t]{2}{*}{ Travel time to treatment center } & $>1 \mathrm{~h}$ & 105.7(0.08) & $1.37(1.22,1.55)$ & $<0.001$ & $1.09(1.02,1.21)$ & $0.03^{*}$ \\
\hline & $\leq 1 \mathrm{~h}$ & 145.14(0.09) & Ref. & & Ref. & \\
\hline Patient delay ${ }^{c}$ & & & $1.003(1.002,1.004)$ & $<0.001$ & $1.003(1.001,1.003)$ & $<0.001^{*}$ \\
\hline Provider delay ${ }^{c}$ & & & $1.002(1.001,1.003)$ & $<0.001$ & $1.002(1.001,1.002)$ & $<0.001^{*}$ \\
\hline \multirow[t]{2}{*}{ Action before HCF visit } & None & 111.85(0.11) & Ref. & & Ref. & \\
\hline & Took action $^{d}$ & $137.34(0.1)$ & $1.23(1.07,1.41)$ & 0.003 & $1.08(0.98,1.28)$ & 0.1 \\
\hline \multirow[t]{2}{*}{ TB diagnosed HCF } & Public & $116.37(0.1)$ & Ref. & & & \\
\hline & Private & $121.27(0.1)$ & $1.04(0.87,1.24)$ & 0.5 & $0.95(0.83,1.09)$ & 0.5 \\
\hline \multirow[t]{3}{*}{ Hospitalized for treatment } & Yes & $240.82(0.1)$ & $2.13(1.61,2.80)$ & $<0.001$ & $2.3(1.84,2.88)$ & \\
\hline & & & & & & $<0.001^{*}$ \\
\hline & No & $113.3(0.1)$ & Ref. & & Ref. & \\
\hline
\end{tabular}

*Statistically significant at $p<0.05$

${ }^{a}$ Exponent to the power of 10

${ }^{b}$ Adjusted for variables in the table

'Variable treated as continuous

${ }^{\mathrm{d} S e l f-t r e a t m e n t, ~ u s e d ~ h o l y ~ w a t e r, ~ c o n s u l t ~ t r a d i t i o n a l ~ h e a l e r ~}$

provider delays all independently predicted increased mean total patient cost of TB care (Additional file 2: Table S2). The mean total cost incurred by patients who are rural residents is about $24 \%$ higher than that by urban residents, adjusted exp. coefficient (AeC) $(95 \% \mathrm{CI}) 1.24(1.13,1.4)$. Similarly, every patient and provider delay day predicts about $0.3 \%$ each $\mathrm{AeC}(95 \% \mathrm{CI})$ 1.003(1.002-1.004) increment in mean total patient cost. Those patients who took action before initiating HCF visits had incurred $17 \%$ higher mean total cost compared to those who did not took action. Hospitalization during anti-TB treatment increase the total mean patient cost by $97 \%$ compared to those not hospitalized.

\section{Discussion}

This follow-up study of new TB cases on DOTS revealed patients incurred substantial cost across pathways to TB treatment. Thus, the median out-of-pocket payment for an episode of TB illness amounted to US\$59.58 that constitutes more than a quarter $(29.4 \%)$ of the total cost. More than half $(53.6 \%)$ of the total cost were incurred before diagnosis of $\mathrm{TB}$, and majority (70.6\%) of the total cost were attributed to nearly 52 lost workdays per patient. Compared to the post-diagnosis, patients incurred significantly higher medical and indirect costs and lower nonmedical costs during the pre-diagnosis period. Increased pre-diagnosis costs were attributed to patient and provider delays, taking informal treatment before $\mathrm{HCF}$ visit, diagnosis at private facilities, being clinically diagnosed, and the number of visited health facilities. On the other hand, rural residence, hospitalization for anti-TB treatment, and following anti-TB treatment at a health center predicted increased post-diagnosis patient costs.

The total cost incurred across the care-seeking and treatment pathways are significantly correlated with both patient and provider delays. The increased pre-diagnosis 
cost with patient delay could be due to increased risks of severe manifestation [27] that lead to hospitalization and companion during care seeking and treatment. Besides, the patient delay is associated with informal care including self-treatment and traditional cares [28, 29] that pose costs to patients. The patient delays are accompanied by longer lost workdays that reduced patient income. On the other hand, the delay at health system (provider delay) is associated with repeated visits to different HCF when patients incur for both medical and nonmedical services.

Those patients diagnosed clinically incur significantly higher pre-diagnosis cost. This could be due to national diagnostic algorithm that respectively requires $2-4$ and 4-8 weeks follow-up for the clinical diagnosis of smear negative and extra pulmonary TB [21]. The higher costs for the clinical diagnosis could be due to the requirement of experienced clinician decisions guided by better diagnostic facilities. Such experts and facilities exist at only few healthcare facilities situated in cities very far from the majority of the people that lead to higher transportation and lodging costs to patients. The repeated consultations and diagnostic tests until diagnosis of $\mathrm{TB}$ all incur cost to the patients. The relatively lower cost of bacteriologically confirmed diagnosis could be due to exemption of sputum smear microscopy and culture by the national TB control program. Hence, ensuring efficient diagnostic algorithms and quality bacteriological tests can reduce the financial burden of TB patients.

Consistent with other studies $[8,30]$ patients diagnosed at private facilities incur significantly higher pre-diagnosis cost compared to those diagnosed at public facilities. The different cost items and rates at the private facilities where every services including sputum microscopy is charged can explain the relatively higher cost at the private. Since there were no public-private mix (PPM)-DOTS in the study area at the time of study, the private HCF might not implement the proper diagnostic algorithm that might lead to delay and extra cost. Furthermore, public health facilities requirement of retesting a positive sputum result from private facilities for treatment initiation leads to delay and extra cost [31].

We found patients treated at hospitals had significantly lower post-diagnosis cost compared to those treated at health center. This could be due to the presence of full-time staff that exclusively provides TB patient care at hospitals. However, at health centers, providers are given multiple duties other than TB DOTS that increase patient waiting time and costs. In addition, health centers are situated in rural areas where there is no transport access within villages in contrast to hospitals in urban areas easily accessible to patients within the town. Thus, statistically significant difference in mean total time (71.17 vs 106 . 79 min, $p<0.001$ ) had been respectively spent per each patient visit to hospitals and health centers. Consistent with other studies [8,32], we found significantly higher post-diagnosis cost incurred by patients from rural areas compared to those from urban areas. The reason could be due to significantly higher mean time spent per each visit among patients that are rural and urban residents (119.51 vs. $68.35 \mathrm{~min}$, $p<0.001$ ), respectively.

Our study had some limitations. First, cost measurements relied on patient recall, which was liable to recall bias. However, we did the baseline interview within the first 2 months of treatment when patients are highly likely to recall about the costs they incurred. Second, the study employed only patient perspective so that we were not able to determine costs incurred by health systems, households, and communities. Lastly, we determined the cost based on a prevalent approach that measure costs for an episode of illness so that we could not determine lifetime cost of TB illness. On the other hand, our study employed a longitudinal design involving a relatively large sample recruited consecutively. As a result, selection bias was minimized and patient costs from care seeking through treatment completion were determined. The findings in the paper are valid but need to be interpreted cautiously considering the limitations. Given the internal validity, the findings can be applied to patients in similar settings since the characteristics of patients and the health systems in similar settings might not differ significantly.

\section{Conclusion}

The study revealed TB patients on DOTS incur substantial cost across the pathways to anti-TB treatment despite the "free service." Significantly, higher cost was incurred during the pre-diagnosis period compared to the post-diagnosis period showing longer pathways of care seeking. Increased pre-diagnosis costs are attributed to patient and provider delays, informal care before consultation, seeking care at private healthcare facilities, and clinical diagnosis. Higher post-diagnosis costs are attributed to patient and provider delays, rural residence, and being treated at health center. Thus, implementation of patientcentered TB care introducing reimbursement mechanisms and scaling up of national community and social insurance initiatives to the study area are vital to reduce patients' out-of-pocket expenditures. In addition, introducing reimbursement of direct costs, promoting early care seeking, equipping healthcare facilities with the necessary equipments, and staffing with qualified health work force, and decentralizing efficient diagnosis and treatment within reach of patients can minimize the patient costs. 


\section{Additional files}

Additional file 1: Consent form and questionnaire. (DOCX $112 \mathrm{~kb}$ )

Additional file 2: Table S1. Mean differences of pre, post, and total costs to patients among TB cases on treatment in districts of southwestern Ethiopia January to December 2015. Table S2. Predictors of total cost to patients among TB cases on treatment in districts of southwestern Ethiopia January to December 2015. (DOCX 25 kb)

\section{Abbreviations}

Cl: Confidence interval; DOTS: Directly Observed Treatment Short course; ETB: Ethiopian Birr; HCF: Healthcare facility; HIV: Human immunodeficiency virus; IOR: Inter-quartile range; PPM: Public-private mix; SD: Standard deviation; TB: Tuberculosis; US\$: United States of America Dollar

\section{Acknowledgements}

We are indebted to Addis Ababa and Mizan-Tepi Universities for financial and material supports for the study. We are also grateful to the patients, data collectors, data clerks, supervisors, and the staffs of study districts and health facilities for their all rounded support to the study.

\section{Funding}

Financial and material support was obtained from Addis Ababa and Mizan-Tepi Universities based in Ethiopia.

\section{Availability of data and materials}

The data from which conclusion of this study was made can be available upon request from the corresponding author.

\section{Authors' contributions}

AA conceived and designed the study, collected and analyzed the data, and prepared the manuscript. WD and DJ critically reviewed the study protocol and manuscript for intellectual content as primary and co-supervisor, respectively. All authors have read and approved the final version of the manuscript.

\section{Ethics approval and consent to participate}

The study was ethically approved by the Institutional Review Board (IRB) of the College of Health Sciences at Addis Ababa University (protocol number: 045/14/sph). Written informed consent was sought from each study participant before the interview. Patient clinical profile from records and a unit register was retrieved upon permission from respective health care facilities.

\section{Competing interests}

The authors declare that they have no competing interests.

\section{Publisher's Note}

Springer Nature remains neutral with regard to jurisdictional claims in published maps and institutional affiliations.

\section{Author details}

'Department of Public Health, College of Health Sciences, Mizan-Tepi University, PO Box 260, Mizan Aman, Ethiopia. ${ }^{2}$ Management Sciences for Health, Addis Ababa, Ethiopia. ${ }^{3}$ Department of Preventive Medicine, School of Public Health, College of Health Sciences, Addis Ababa University, Addis Ababa, Ethiopia.

\section{Received: 11 October 2017 Accepted: 8 May 2018}

Published online: 21 May 2018

References

1. World Health Organization. Global tuberculosis report. Switzerland: World Health Organization; 2016

2. Laxminarayan R, Klein E, Dye C, Floyd K, Darley S, Adeyi O. Economic benefit of tuberculosis control. World Bank. 2007

3. World Health Organization: An expanded DOTS framework for effective tuberculosis control. 2002

4. World Health Organization. In: WHO, editor. The end TB strategy: global strategy and targets for tuberculosis prevention, care and control after 2015; 2015.
5. Tanimura T, Jaramillo E, Weil D, Raviglione M, Lonnroth K. Financial burden for tuberculosis patients in low- and middle-income countries: a systematic review. Eur Respir J. 2014;43(6):1763-75

6. KNCV, WHO, JATA. The tool to estimate Patients'Costs. In: KNCV Tuberculosis Foundation, World Health Organization, Japan Anti-Tuberculosis Association; 2008.

7. Barter D, Agboola S, Murray M, Barnighausen T. Tuberculosis and poverty: the contribution of patient costs in sub-Saharan Africa-a systematic review. BMC Public Health. 2012:12:980.

8. Ukwaja K, Alobu I, Lgwenyi C, Hopewell P. The high cost of free tuberculosis services: patient and household costs associated with tuberculosis care in Ebonyi State, Nigeria. PLoS One. 2013;8(8):e73134.

9. Othman G, Ibrahim M, Raja'a Y. Costs associated with tuberculosis diagnosis and treatment in Yemen for patients and public health services. Eastern Mediterranean health journal $=$ La revue de sante de la Mediterranee orientale = al-Majallah al-sihhiyah li-sharq al-mutawassit. 2012:18(4):393-8.

10. Aspler A, Menzies D, Oxlade O, Banda J, Mwenge L, Godfrey-Faussett P, Ayles $\mathrm{H}$. Cost of tuberculosis diagnosis and treatment from the patient perspective in Lusaka, Zambia. Int J Tuberc Lung Dis. 2008;12(8):928-35.

11. Finnie R, Khoza L, Van den Borne MT, Abotchie P, Mullen P. Factors associated with patient and health care system delay in diagnosis and treatment for TB in sub-Saharan African countries with high burdens of TB and HIV. Tropical Med Int Health. 2011;16(4):394-411.

12. Wingfield $T$, Tovar $M$, Huff $D$, Boccia $D$, Saunders $M$, Datta $S$, Montoya $R$, Ramos $E$, Lewis J, Gilman R, et al. Beyond pills and tests: addressing the social determinants of tuberculosis. Clinical medicine. 2016;16 (Suppl 6):s79-91.

13. Long Q, Smith H, Zhang T, Tang S, Garner P. Patient medical costs for tuberculosis treatment and impact on adherence in China: a systematic review. BMC Public Health. 2011;11:393.

14. Faustini A, Hall J, Perucci A. Risk factors for multidrug resistant tuberculosis in Europe: a systematic review. Thorax. 2006;61:158-61.

15. Pooran A, Pieterson E, Davids M, Theron G, Dheda K. What is the cost of diagnosis and management of drug resistant tuberculosis in South Africa? PLoS One. 2013:8(1):e54587.

16. WHO. Global tuberculosis report. In: World Health Organization; 2015.

17. Federal Democratic Republic of Ethiopia Ministry of Health. Ethiopia's Fourth National Health Accounts, 2007/08. Addis Ababa: Federal Democratic Republic of Ethiopia Ministry of Health; 2010.

18. Verguet $\mathrm{S}$, Memirie $\mathrm{S}$, Norheim $\mathrm{O}$. Assessing the burden of medical impoverishment by cause: a systematic breakdown by disease in Ethiopia. BMC Med. 2016;14(1):164.

19. Mesfin M, Newell J, Madeley R, Mirzoev T, Tareke I, Kifle Y, Gessessew A Walley J. Cost implications of delays to tuberculosis diagnosis among pulmonary tuberculosis patients in Ethiopia. BMC Public Health. 2010;10:173.

20. Datiko D, Lindtjorn B. Cost and cost-effectiveness of smear-positive tuberculosis treatment by Health Extension Workers in Southern Ethiopia: a community randomized trial. PLoS One. 2010:5(2):e9158.

21. Federal Minstry of Health of Ethiopia. Guidelines for clinical and programmatic management of TB, leprosy and TB/HIV in Ethiopia. 5th ed. Addis Ababa: Ethiopian Federal Minstry of Health; 2012

22. Federal Democratic Republic of Ethiopia Central Statistical Agency. Population projection of Ethiopia for all regions at Wereda level from 2014 2017. Addis Ababa: Central Statistical Authority; 2013.

23. Southern Nation Nationalities Peoples Region Health Bureau. Annual performance report. Hawassa: SNNPR HB; 2014.

24. World Health Organization. Treatment of tuberculosis: guidelines. Geneva: World Health Organization; 2010.

25. WHO. Guide to identifying the economic consequences of disease and injury. Geneva; 2009

26. National Bank of Ethiopia. Inter-bank daily foreign exchange rate in (USD)_archive. In: National Bank of Ethiopia; 2015

27. Virenfeldt J, Rudolf F, Camara C, Furtado A, Gomes V, Aaby P, Petersen E, Wejse C. Treatment delay affects clinical severity of tuberculosis: a longitudinal cohort study. BMJ Open. 2014;4(6):e004818.

28. Belkina T, Khojiev D, Tillyashaykhov M, Tigay Z, Kudenov M, Tebbens J, Vlcek J. Delay in the diagnosis and treatment of pulmonary tuberculosis in Uzbekistan: a cross-sectional study. BMC Infect Dis. 2014;14:624.

29. Laokri S, Amoussouhui A, Ouendo E, Hounnankan A, Anagonou S, Gninafon M, Kassa F, Tawo L, Dujardin B. A care pathway analysis of tuberculosis 
patients in Benin: highlights on direct costs and critical stages for an evidence-based decision-making. PLoS One. 2014;9(5):e96912.

30. Lambert M, Delgado R, Michaux G, Volz A, Speybroeck N, Van Der Stuyft P. Delays to treatment and out-of-pocket medical expenditure for tuberculosis patients, in an urban area of South America. Ann Trop Med Parasitol. 2005; 99(8):781-7.

31. Yimer S, Hansen C, Bjune G. The perspective of private practitioners regarding tuberculosis case detection and treatment delay in Amhara region, Ethiopia: a cross-sectional study. BMC Res Notes. 2011;4:285.

32. Ukwaja K, Alobu I, Abimbola S, Hopewell P. Household catastrophic payments for tuberculosis care in Nigeria: incidence, determinants, and policy implications for universal health coverage. Infectious Disease of Poverty. 2013;2(1):21

Ready to submit your research? Choose BMC and benefit from:

- fast, convenient online submission

- thorough peer review by experienced researchers in your field

- rapid publication on acceptance

- support for research data, including large and complex data types

- gold Open Access which fosters wider collaboration and increased citations

- maximum visibility for your research: over $100 \mathrm{M}$ website views per year

At BMC, research is always in progress.

Learn more biomedcentral.com/submissions 